\title{
EL INTELECTUAL LATINOAMERICANO ANTE LA REVOLUCIÓN: ALEJO CARPENTIER Y LA CONSAGRACIÓN DE LA PRIMAVERA
}

TEOdosio FERnÁNDEZ

Universidad Autónoma de Madrid

teodosio.fernandez@uam.es

\section{RESUMEN}

La relación entre los intelectuales y la Revolución cubana vivió un período difícil en la década de 1970, cuando la política impuesta desde La Habana resultó incompatible con la libertad reclamada por los escritores. En su novela La consagración de la primavera, Alejo Carpentier trató de acercar a las exigencias revolucionarias la propuesta literaria que tiempo atrás lo había identificado con la invención de lo real maravilloso americano.

PALABRAS ClAVE: intelectual, revolución, mito, La consagración de la primavera.

\section{Abstract}

The relationship between intellectuals and the Cuban Revolution faced a difficult period during the seventies, when the political line launched at La Habana seemed to be irreconcilable with the freedom demanded by writers. In his novel The Rite of Spring, Alejo Carpentier tried to bring his own and well-recognized literary proposal, linked to the invention of American magical realism, closer to the demands of the Revolution.

KEY wORDS: Intellectual, Revolution, Myth, The Rite of Spring.

En 1971 la detención del poeta Heberto Padilla y su posterior autoinculpación volvieron tensas las relaciones otrora excelentes entre la Revolución cubana y algunos de 
los representantes más destacados de la «nueva novela latinoamericana». Las diferencias habían empezado a ser notorias tras la muerte de Ernesto Che Guevara en Bolivia, el 7 de octubre de 1967, cuando los leales al régimen castrista plantearon con radicalismo creciente la necesidad de elegir entre la libertad del escritor y su adhesión incondicional al proceso revolucionario, e incluso defendieron el abandono de la literatura por la lucha armada. Consecuentes con su posición, ahora denunciaban con insistencia la escisión entre el ser político y el ser literario observada en algunos novelistas famosos - los entonces identificados con el boom de aquella narrativa-, o el contraste entre sus declaraciones revolucionarias y la actitud escapista que a veces demostraban con obras ajenas al contexto social y político de Latinoamérica. Frente a quienes parecían empeñados en constituir una élite cultural sin haberse insertado en el drama y en la heroicidad de la revolución, Fidel Castro y Ernesto Che Guevara se convertían en los intelectuales verdaderos, cuya jerarquía moral determinaba la de los demás. En la sociedad socialista, por otra parte, el papel crítico o subversivo del escritor parecía destinado a desaparecer, pues no sería otra cosa que una fuerza al servicio del enemigo.

Carpentier había contribuido al auge de la nueva novela latinoamericana sobre todo con El Siglo de las Luces, que en 1962 puso en circulación la mexicana Compañía General de Ediciones. Las rebeliones inútiles de los negros haitianos recreadas años atrás en El reino de este mundo no habían agotado su interés por las repercusiones americanas de la Revolución francesa, que abordaba en otra conjugación de fantasía e historia centrada en las actividades de Victor Hugues, Comisario de la Convención en la Guadalupe y Agente del Directorio en Cayena, complementadas y a la vez comentadas por Sofía, Carlos y Esteban, los jóvenes cubanos que compartían el protagonismo de la novela. Algunos comentarios elogiosos suscitados por la nueva narrativa en los años sesenta se volvían problemáticos para Carpentier en los setenta, como los que Carlos Fuentes había incluido en La nueva novela hispanoamericana: «La fusión de moral y estética tiende a producir una literatura crítica, en el sentido más profundo de la palabra: crítica como elaboración antidogmática de problemas humanos $»^{1}$, observaba el novelista mexicano a propósito de algunas novelas recientes, y, aunque no quería ver en El Siglo de las Luces «una alegoría que ilustre el destino de las revoluciones» — todavía trataba de salvar los puentes con Carpentier y con la Revolución cubana-, prefería deducir de los hechos relatados que «la libertad es idéntica a una aspiración permanente, la de hombres que viven en la ambigüedad y no la aceptan, sino que mantienen la exigencia de valores humanos absolutos a sabiendas de que la realidad los niega o los impide» ${ }^{2}$. Tales apreciaciones, inocuas en otras circunstancias, podían convertirse en una incomodidad por provenir de Fuentes, que con los años había dejado de personificar al nuevo intelectual latinoamericano, culto y cosmopolita, para representar la ideología «enajenada y enajenante» del intelectual colonizado ${ }^{3}$.

Tras visitar en enero de 1967 el Vietman atropellado por el imperialismo norteamericano, Carpentier se había instalado en París como Ministro Encargado de Asuntos Cultu-

Carlos Fuentes, La nueva novela hispanoamericana, México, Editorial Joaquín Mortiz, 1969, p. 35.

2 Ibídem, p. 55.

3 Véase Roberto Fernández Retamar, «Calibán», Casa de las Américas, número 68, septiembre-octubre de 1971, pp. 124-151 (144). 
rales. Aun protegido por su condición de diplomático de la Revolución, difícilmente podía evitar que se asociara su nombre al de los escritores del boom que —como Fuenteshabían dejado sus países de origen para afincarse en Europa, lo que desde el bando revolucionario más radical tendía a interpretarse como una deserción a medida que la figura del intelectual comprometido iba quedando en entredicho. Pruebas de que esa asociación se producía pueden encontrarse en quienes precisamente trataban de evitarlo, como en Mario Benedetti cuando, para oponerlo a Guillermo Cabrera Infante y Severo Sarduy, se refería a «un creador como Alejo Carpentier, cubano como ellos pero revolucionario (reside en París, pero ocupando un alto cargo en la embajada cubana)» ${ }^{4}$, alejándolo al mismo tiempo del fenómeno meramente publicitario en que el boom se había convertido para sus detractores. Por otra parte, los argumentos en favor de su lealtad al castrismo no impedían advertir que El Siglo de las Luces permitía extraer de la revolución y los revolucionarios valoraciones menos cautelosas que las aducidas por Fuentes. Sobraban razones para no ver en Victor Hugues otra cosa que un cínico oportunista capaz de imponer a toda costa unos ideales que también estaba presto a traicionar. De la Revolución francesa y de sus repercusiones en América tal como se recreaban en la novela ningún resumen podría hacerse mejor que el de Esteban al recordar sus experiencias como una pesadilla «de incendios, persecuciones y castigos» ${ }^{5}$. De su desaparición y la de Sofía en los tumultos provocados en Madrid por la presencia de las tropas napoleónicas, al iniciarse el mes de mayo de 1808, no cabía sacar conclusiones positivas que el texto permitiera justificar, e incluso se podía deducir que eran los hombres de acción como Hugues quienes traicionaban los ideales de la revolución a la vez que la hacían, mientras los idealistas como Esteban y Sofía apostaban por ella más allá del desencanto y hasta la muerte.

En la tensa atmósfera de los primeros años setenta esos planteamientos podían provocar suspicacias sin fin. Los fieles al régimen cubano se mostraban por entonces convencidos de que «una Revolución no se argumenta: se hace» ${ }^{6}$, tal como había establecido Victor Hugues, quien también se había anticipado al desdeñar las quejas planteadas por Esteban a propósito del desprecio con que se trataba a las gentes de la cultura: «Estamos transformando la vida del hombre, pero se duelen de que unas gentes de letras no puedan reunirse ya para leer idilios y pendejadas» ${ }^{7}$. Cualquiera podría relacionar esa actitud con la de Fidel Castro cuando el 30 de abril de 1971, en el «Discurso de clausura» del Primer Congreso Nacional de Educación y Cultura, respondió a las protestas por el proceso y la autocrítica de Padilla menospreciando a quienes creían que los problemas de Cuba eran los «de dos o tres ovejas descarriadas» a los que se negaba el derecho «a seguir sembrando el veneno, la insidia y la intriga en la Revolución» ${ }^{8}$. Desde luego, Carpentier aún tenía en su haber y en su favor la invención de «lo real maravilloso americano», propuesta en el artículo publicado con ese título en El Nacional de Caracas en 1948 y luego como introducción a El reino de este mundo, lo que permitía analizar sus obras en función del

\footnotetext{
${ }^{4}$ Mario Benedetti, «El boom entre dos libertades», Marcha, números 1434 (30-31) y 1435 (30-31), 24 y 31 de enero de 1969), II, p. 31.

5 El Siglo de las Luces, La Habana, Ediciones R, 1963, p. 157.

${ }^{6}$ El Siglo de las Luces, p. 175.

7 Ibíd., p. 148.

${ }^{8}$ Fidel Castro, «Discurso de clausura del Primer Congreso Nacional de Educación y Cultura», Casa de las Américas, número 65-66, marzo-junio de 1971, pp. 21-33 (26).
} 
realismo mágico y también de la expresión barroca con que sus obras respondían a la pretensión adánica de nombrar el mundo americano. Pero esa justificación, que asignaba a la imaginación la tarea de subvertir el lenguaje del poder, también estaba en entredicho. $\mathrm{Al}$ reseñar La última mujer y el próximo combate, de Manuel Cofiño López (Premio Casa de las Américas en 1971), el ensayista y crítico cubano José Antonio Portuondo hablaba de «una realización feliz de novela revolucionaria», lo que carecería aquí de interés si no hubiera sido valorada como tal en perjuicio claro de la propuesta iniciada por Carpentier y culminada por Gabriel García Márquez con Cien años de soledad: «El Plan de desarrollo forestal y agrario en el que transcurre la novela es el polo opuesto de Macondo», resumía Portuondo, antes de explicar, por si fuera necesario: «Lo mágico, lo "real maravilloso" es aquí la visión caduca y pintoresca, mítica, que va quedando atrás, sobrepasada sin violencia por la nueva conciencia socialista, científica, revolucionaria»"

El escritor leal a la Revolución debía evitar actitudes que se pudieran estimar vacilantes o pseudoizquierdistas, y la mera defensa de la libertad para la cultura figuraba ya entre los mitos burgueses que había que dejar atrás. Esas circunstancias, que condicionaron la trayectoria de numerosos narradores hispanoamericanos, fueron acuciantes sobre todo para los cubanos a partir del Congreso Nacional de Educación y Cultura de 1971, sin que el Primer Congreso del Partido Comunista de Cuba, celebrado en diciembre de 1975, modificara esencialmente la situación, determinada por la persistente convicción de que se asistía a «la confrontación ideológica mundial de la cultura humanista del socialismo con las expresiones enajenantes de la cultura del capitalismo y el imperialismo» ${ }^{10}$. Los escritores debían evaluar su contribución al logro de los objetivos de la sociedad revolucionaria, y sabían que sus obras habrían de ser juzgadas en esos términos. Puesto que nunca se impusieron directrices precisas a la creación literaria -aunque los defensores del realismo socialista encontraron por entonces ocasiones sobradas para manifestarse—, resultaba evidente que preocupaba sobre todo la orientación ideológica de las ficciones, lo que poco tenía que ver con cuestiones artísticas y mucho con la escala de valores que pudiera deducirse de los hechos narrados. No en vano desde 1968 se había ido imponiendo una visión positiva de la Revolución y de sus héroes, y esa visión era ahora la única legítima. El fin del gobierno de la Unidad Popular en Chile, el 11 de septiembre de 1973, proporcionaría una razón más para ser intolerantes con el enemigo. Otras llegarían desde el Uruguay, donde el 27 de junio de aquel mismo año un golpe de estado había abierto el camino hacia otra dictadura represiva, y desde la Argentina, donde el 24 de marzo de 1976 una junta militar desplazó del poder al peronismo e inició un brutal Proceso de Reorganización Nacional.

La adecuación a tales planteamientos resultaba sin duda complicada para Carpentier. La revista Casa de las Américas publicó en 1969 la versión definitiva de una conferencia que él había impartido en francés en los Rencontres Internationales celebrados en Ginebra dos años atrás, en la que no eludía los problemas que entonces afrontaba el compromiso del escritor, pero los diluía entre consideraciones sobre la incapacidad de la litera-

9 José Antonio Portuondo, «Una novela revolucionaria», Casa de las Américas, 71, marzo-abril de 1972, pp. 105-106.

10 «Documentos del Primer Congreso del Partido Comunista de Cuba. Sobre la cultura artística y literaria», Casa de las Américas, número 99, noviembre-diciembre de 1976, pp. 2-25 (8). 
tura para dar cuenta de los avances del mundo contemporáneo y entre reflexiones sobre la novela, que estimaba viva si era épica, y épica si expresaba realidades de su tiempo. Sin duda recordaba el final de El reino de este mundo al concluir que «el gran trabajo del hombre sobre esta tierra consiste en querer mejorar lo que es» ${ }^{11}$, con lo que guardaría relación la tarea asignada al novelista. Entre esas divagaciones se perdían también sus referencias al intelectual como hombre que diría «no» para defender la necesidad de decir «sí» a las grandes tareas colectivas, «a favor de Viet-Nam, de la Revolución Cubana, de la lucha del Tercer Mundo contra el poder imperialista» ${ }^{12}$. Carpentier declaraba también que la función de novelista era la de entenderse con el «pueblo combatiente», de «criticarlo, exaltarlo, pintarlo, amarlo, tratar de comprenderlo», para hablar de él a quienes sintieran o no la necesidad de que se les dijera algo para removerlos ${ }^{13}$, planteamiento que el antiintelectualismo creciente ya iba dejando obsoleto en la Cuba revolucionaria de 1969. En buena medida los escritores habían perdido para esa fecha la autoridad moral que ellos mismos se habían arrogado para orientar al pueblo, ahora en marcha hacia su liberación definitiva.

En ese contexto El Siglo de las Luces representaba una ambigüedad crítica que ya no resultaba aceptable, y ni El recurso del método ni Concierto barroco, las novelas que Carpentier dio a conocer en los años setenta — publicadas en México por Siglo XXI Editores en 1974 y 1975, respectivamente-, respondían adecuadamente a las nuevas circunstancias. Tras recibir el Premio Cervantes en abril de 1978, de manos del rey de España, se cuidó bien de insistir, al menos para Cuba —el galardón podía despertar las susceptibilidades propias del caso—, en que estaba escribiendo su obra «más ambiciosa, más política y muy decididamente revolucionaria» ${ }^{14}$, a la vez que proclamaba su adhesión beligerante y sin concesiones a la Revolución cubana, así como su desconfianza radical en la neutralidad de la cultura que desde otros frentes se propugnaba. Sin renunciar a sí mismo y a la condición de intelectual que él representaba inevitablemente — con su propensión al barroquismo verbal y a los excesos descriptivos al proponer una síntesis cultural americana, lo que le daba ocasión para ostentar una erudición enciclopédica-, se había decidido por fin a abordar un tema relacionado con la historia cubana reciente, tal como se le reclamaba desde tiempo atrás, lo que le permitió volver sobre su propio pasado y ofrecer una imagen mejorada de su compromiso anterior con las causas que ahora defendía. Como es sabido, el cubano Enrique y la rusa Vera le sirvieron para recordar episodios relevantes de la historia del mundo occidental en el siglo xx — la revolución soviética, la guerra civil española, la segunda guerra mundial, sin olvidar los avatares que afectaron a Cuba - hasta concluir con los días triunfales de abril de 1961, cuando las Fuerzas Armadas revolucionarias rechazaron la invasión de los cubanos exiliados que, con ayuda norteamericana, desembarcaron en Playa Girón, en la Bahía de Cochinos, episodio bélico tras el que Fidel Castro confirmó el carácter socialista y marxista de su régimen.

11 «Papel social del novelista», Casa de las Américas, IX, 53, marzo-abril 1969, pp. 8-18 (18).

12 Ibíd., p. 16.

13 Ibíd., p. 18.

14 Jorge Timossi, «Alejo Carpentier: la identidad latinoamericana», Casa de las Américas, número 109, julio-agosto de 1978, pp. 86-90 (89). Esa revista había anticipado el capítulo 5 de la primera parte casi en su totalidad (número 96, mayo-junio de 1976, pp. 72-76), y también el 1 de esa primera junto al final del 1 de la tercera (número 101, marzo-abril de 1977, pp. 91-104). 
Naturalmente, Carpentier no podía prescindir de su pasado, que fundió con el de sus personajes y en particular con el de Enrique para mostrar el nacimiento problemático de una conciencia socialista a partir del horror a la arbitrariedad, a la injusticia y a los abusos de poder. Se incorporaba así al tratamiento de un tema que los novelistas cubanos habían abordado con insistencia: el de los hombres «de transición» que trataban de superar el pecado original de su pasado burgués para adecuarse a la condición del «hombre nuevo» exigido por la revolución. A pesar de proceder de una hedionda y adinerada alta burguesía cubana con ínfulas aristocráticas — las de su tía la condesa—, de disfrutar de sus ventajas y de compartir sin sonrojarse el indudable refinamiento que su clase social había alcanzado, Enrique cumplía ese proceso sin otras vacilaciones que la necesarias para hacerlo creíble y a la vez permitir la recreación de sus circunstancias históricas: había llegado a la guerra civil española con las Brigadas Internacionales, tras aprender a pensar por sí mismo con la ayuda del comunista Julio Antonio Mella y haber comprometido su posición acomodada sumándose a quienes combatían la dictadura del general Gerardo Machado, y volvería a empuñar las armas al servicio de la Revolución cubana que ya daba sentido pleno a su vida. Los episodios relacionados con la lucha heroica contra el régimen dictatorial de Fulgencio Batista — el desembarco de los guerrilleros del Granma, la guerra desde Sierra Maestra hasta el triunfo final— se habían conjugado con la presentación de un país cuya condición de casino y burdel coincidía con la visión oficial proyectada por el castrismo sobre el pasado republicano. La ambigüedad crítica de la nueva novela se había transformado así en certeza heroica, acorde con la condición épica asignada a los tiempos presentes, y en adhesión incondicional a la Revolución, incluso al valorar el estilo «distinto, innovador, claro, dialéctico» ${ }^{15}$ del discurso pronunciado por Fidel Castro en Caracas cuando Carpentier residía aún en Venezuela.

En el proceso histórico recreado debían integrarse los intereses culturales y las inquietudes artísticas que habían estado íntimamente ligados a la obra literaria de Carpentier, y que volvían a manifestarse en La consagración de la primavera desde el mismo título de la novela. La compleja recreación del pasado ofrecida en sus páginas resulta inabordable aquí y ahora, lo que no impide señalar algunos aspectos relacionados con el esfuerzo para acomodar la rememoración a la fe revolucionaria del presente. Con eso tiene que ver la contraposición planteada entre la actitud de quienes se alistaban en las Brigadas Internacionales para luchar en España contra el fascismo — como Enrique o como el hispanista Jean-Claude Lefevre, por entonces amante de Vera- y la palabrería izquierdista que había invadido Montparnasse en los años treinta, de la mano de quienes allí y entonces se erigían en guardianes de la pureza revolucionaria, lo que en los setenta debía leerse en términos del enfrentamiento entre el régimen castrista y la gauche divine europea y latinoamericana que había interpretado el caso Padilla como una traición a los principios de la Revolución cubana. Cualesquiera que fuesen las circunstancias - la guerra civil española, la segunda guerra mundial, la lucha contra el régimen de Fulgencio Batista y contra la agresión norteamericana-, a las disputas teóricas se prefería la acción armada, lo que ponía de manifiesto la voluntad de dejar a un lado la literatura cuando las

15 La consagración de la primavera, Madrid, Siglo XXI Editores, 1978, p. 521. Las citas corresponden siempre a esta edición y en adelante aparecerán seguidas de $C P$ y el número de las páginas correspondientes. 
circunstancias lo requerían, en consonancia con la exaltación revolucionaria que había cuestionado la legitimidad del escritor.

Entre los aspectos de La consagración de la primavera que revelaban la voluntad de adecuar la creación artística al programa de la revolución, no es el de menor interés la discusión sobre la condición del arte en Latinoamérica que a veces se apuntaba, y no tanto en relación con el pasado como con el presente ${ }^{16}$. Apenas se había liberado de la tradición española representada por los cuadros exhibidos en la mansión familiar para disfrutar de los valores estrictamente plásticos impuestos por la vanguardia, Enrique volvía a encontrarse — en los frescos de Diego Rivera o de José Clemente Orozco- con una pintura «altamente figurativa, narrativa, furiosamente significante» $(C P, 64)$, precisamente en México, donde la palabra «revolución» era de uso permanente y decirse «revolucionario» constituía una declaración de principios. La referencia adquiría una significación relevante en el contexto literario de los setenta, cuando desde los sectores próximos a la dirigencia revolucionaria se extendía el rechazo hacia las manifestaciones más experimentales de la nueva novela latinoamericana. Por supuesto, la estancia de Enrique en París dio ocasión a Carpentier para reiterar su ya antigua descalificación del surrealismo y de las preferencias artísticas y literarias en que se apoyaba, pero ahora - aunque aprovechaba alguna ocasión para registrar en La Habana la presencia de lo surrealista «en estado bruto» $(C P, 336-337)$, según su difundida teoría de lo real maravilloso americano - prefería orientar el menosprecio hacia el tipo burgués de libertad propuesto por André Breton, para luego, con Enrique en Nueva York y a propósito de la revista $V V V$, centrarlo en la resistencia del intelectual a dar su plena adhesión a una causa justa, resistencia ejemplificada con el propio Breton y su tendencia a decir «no» incluso cuando se trataba de tomar partido por la resistencia soviética contra el nazismo. Sobradas razones asistían a Enrique cuando alguna vez aseguró haber perdido todo interés por «los hacedores de literatura» $(C P, 230)$, actitud que propuesta por Carpentier no podía ser sino una muestra de su voluntad de acercarse al antiintelectualismo de la Revolución cubana, justificado por la incapacidad de los escritores para dar respuestas a los conflictos, mientras se distraían en defender una libertad inútil y se decepcionaban en cuanto la realidad dejaba de acomodarse a sus expectativas personales.

En el contexto revolucionario de la época, en La consagración de la primavera merecen especial atención las múltiples referencias relacionadas con la condición de músico y musicólogo de Carpentier. Apenas iniciada la obra, mientras el tren en que viaja se acerca a los Pirineos, Vera evoca otras montañas ante las que los hombres del Caballo y de la Rueda detuvieron su errancia incesante y,

sintiendo en sus venas el pálpito de los augurios primaverales, procedieron a la invocación ritual de los ancestros, pasearon en hombros al sabio que ya solo hablaba por la oquedad de sus huesos y, teniendo que ungir la tierra con la sangre de una doncella, lloraron todos al invocar

\footnotetext{
${ }^{16}$ Significativamente, Casa de las Américas había recuperado una «Carta abierta a Manuel Aznar sobre el meridiano intelectual de nuestra América» que Carpentier había dirigido al director del Diario de la Marina —allí se publicó el 12 de septiembre de 1927—, donde la polémica suscitada entonces por el semanario madrileño La Gaceta Literaria servía de pretexto para subrayar las peculiaridades de las manifestaciones artísticas de América, espacio en el que la vigencia de preocupaciones cívicas o revolucionarias harían improcedentes las propuestas de un arte puro o deshumanizado. Véase Casa de las Américas, número 84, mayo-junio de 1974, pp. $147-150$.
} 
a la Virgen Electa - lloraron todos, clamando su compasión, lacerando sus vestidos, cerrando con lágrimas las secuencias de sus danzas de fecundidad, al pagar el cruento precio exigido para que hubiese un nuevo júbilo de retoños y de espigas $(C P, 12)$.

Esa antigua leyenda, sacada acaso de aquella Epopeya de los Nartas que contaba a Vera el jardinero de su padre - Carpentier pudo leerla en Légendes sur les Nartes, suivies de cinq notes mythologiques, de Georges Dumézil, volumen que el Institut d'Études Slaves publicó en París en 1930_, era, como el lector podrá adivinar, la leyenda caucásica que inspiró a Igor Stravinski La consagración de la primavera, que los Ballets Rusos de Serge Diaghilev estrenaron el 29 de mayo de 1913 en el recién construido Théâtre des Champs-Élysées de la capital francesa, con partitura de Stravinski, coreografía de Vaslav Nijinski y decorado y vestuario de Nicholas Roerich. Carpentier conocía bien las aportaciones de los Ballets Rusos: lo demostraba ya en «León Bakst», artículo que escribió a la muerte del gran escenógrafo, ocurrida en París a fines de 1924, ocasión que aprovechó también para referirse al «temperamento místico, conventual, de Roerich» ${ }^{17}$. Entre los ensayos en que se ocupó del tema, especial interés ofrece «La evolución estética de los Ballets Rusos», donde dio cuenta del orientalismo inicial, cuyos excesos decorativos se verían atenuados en Petruchka y La consagración de la primavera, para ser eliminados drásticamente con los decorados que Pablo Picasso pintó para Parade en 1917, iniciando una evolución favorable a la sobriedad que él identificó con el «espíritu nuevo» de la vanguardia, asociado sobre todo al cubismo y sus consecuencias ${ }^{18}$. Saberes como esos están muy presentes en la novela a través de Vera, cuyas imaginarias experiencias con los Ballets Rusos de Diaghilev y luego con el Ballet Ruso de Montecarlo daban ocasión para recrear las vividas por Carpentier en los años veinte y treinta, cuando en espectáculos y en música llegados de España y de América decía encontrar el impulso vivificador que Europa necesitaba para reanimar sus decadentes manifestaciones culturales.

Las minuciosas referencias a los Ballets Rusos interesan aquí menos por lo que dicen sobre ellos que por la función atribuida en la novela a La consagración de la primavera, función relevante tanto por el mito y el rito que Stravinski recuperaba como por los procedimientos artísticos empleados en su recreación. Significativamente, Carpentier relacionó con la compañía del coronel Wassily de Basil, cofundador del Ballet Ruso de Montecarlo, la pretensión de conseguir una versión del espectáculo que olvidara «la absurda coreografía ruso-dalcroziana del estreno, no muy superada, para decir la verdad, por la harto esquemática concepción de Massine, en 1920» $(C P, 185)$. Parecía desdeñar los dos primeros montajes de la obra, que imaginaba a su gusto, pues no los había visto ${ }^{19}$, para proponer algo diferente que potenciase o al menos expresara la pulsión telúrica, elemental, de una liturgia tribal destinada a propiciar un nuevo ciclo nutricio de la naturaleza. El sacrificio de la doncella en el ballet de Stravinski y el de Vera mientras ensayaba en París La consagración de la primavera, muerta en vida tras el sacrificio (otro más) de

17 «León Bakst» (Social, volumen 10, número 21, febrero de 1925), en Alejo Carpentier, Crónicas 2. Arte, literatura y política, México, Siglo XXI Editores, 1986, pp. 11-16.

18 Alejo Carpentier, «La evolución estética de los Ballets Rusos» (Social, volumen 14, número 4, abril de 1929), Crónicas 2. Arte, literatura y política, pp. 170-175.

${ }_{19}$ El Joffrey Ballet recuperó la representación inicial y la presentó en Los Ángeles en 1987. La coreografía de Nijinski fue reconstruida por Millicent Hodson, y Kenneth Archer hizo otro tanto con el decorado y el vestuario de Nicholas Roerich. Nada justificaba las opiniones de Carpentier. 
Jean-Claude Lefevre en la guerra civil española —en el Coll del Cosso, episodio de la batalla del Ebro que permite fechar su fallecimiento en los primeros días de octubre de 1938 - se entreveraban enriqueciendo mutuamente sus significados, que cabía asociar con la esperanza de nuevas primaveras y también, sin optimismo, con la reiteración fatal de ofrendas a divinidades siempre insatisfechas. Después de establecer su relación sentimental — privados de sus amantes previos por el nazismo alemán y el fascismo español, respectivamente-, Enrique y Vera tendrían nuevas ocasiones para sentirse inmersos en un tiempo circular en el que cada resurgir parecía la premonición de un nuevo sacrificio: «¿Habré de ser otra vez sembrado?» $(C P, 195)$, rezaba el epígrafe, extraído de un poema náhuatl, que había introducido la tercera parte de la novela.

Carpentier no podía ignorar los riesgos de la ambigüedad cuando desde el bando revolucionario se estaba forzando una interpretación progresista de El reino de este mundo y de El Siglo de las Luces, prueba evidente de que esas novelas la necesitaban. Entre quienes participaron en el homenaje que en 1974 le dedicó Casa de las Américas al cumplir los setenta años, estaba Lev Ospovat, preocupado por alejar de Carpentier los aspectos «desmovilizadores» de los mitos, que al cabo resultaban inseparables de las creencias religiosas - no solo de las primitivas- y en consecuencia sospechosos. Al hispanista soviético le inquietaba especialmente la identificación de las rebeliones y derrotas de los negros haitianos con el mito de Sísifo, lo que había inducido a investigadores «burgueses» a ver en El reino de este mundo una alegoría pesimista e incluso contrarrevolucionaria sobre el destino de las revoluciones ${ }^{20}$. Por supuesto, tampoco resultaban aceptables las consideraciones existencialistas a lo Albert Camus sobre la lucidez del hombre capaz de afrontar su condición absurda de condenado a trabajos inútiles e incesantes, y de entrever en esa condena momentos fugaces de libertad. En La consagración de la primavera ya no podía haber lugar para los equívocos, de modo que los fracasos previos tenían que convertirse claramente en episodios de una guerra que habría de conducir a la victoria final. Para que la reorientación de los planteamientos no resultase abrupta, Carpentier hizo que Vera, ya en Cuba, presenciara una danza giratoria de un diablito abakuá y los saltos de un baile arará, obligándola a concluir: «Si Nijinski hubiese contado con bailarines así, su coreografía primera de La consagración de la primavera no hubiese sido el fracaso que fue. Era esto lo que pedía la música de Stravinsky: los danzantes de Guanabacoa, y no los blandengues y afeminados del ballet de Diaghilev» $(C P, 260)$.

Carpentier aprovechó la ocasión también para recrear una conversación en la que sus personajes recordaban un ceremonial de iniciación abakuá y otro del vodú haitiano de rito canzó en los que la mujer a punto de ser sacrificada era sustituida por un animal, al igual que Ifigenia, variaciones sobre un mismo tema que admitía soluciones diversas. Peor les había ido a la hija de Jefté en la Biblia o a las vírgenes electas de la leyenda caucásica, otras pruebas de la universalidad de mitos y rituales, evocados con una fascinación manifiesta. Vera se acercaba a las convicciones sostenidas tiempo atrás por el novelista: ellas tenían que ver ahora con la pretensión de superar el preciosismo de Nijinski

${ }^{20}$ «El hombre y la historia en la obra de Alejo Carpentier», Casa de las Américas, número 87, noviembrediciembre de 1974, pp. 9-17 (13). Inquietudes similares pueden encontrarse en Carlos Rincón, «Sobre Alejo Carpentier y la poética de lo real maravilloso americano», Casa de las Américas, número 89, marzo-abril de 1975, pp. 40-65 (61). 
o el dalcrozianismo de Marie Lambert — la asistente del bailarín y esa vez coreógrafo resultaba así asociada a la euritmia preconizada por el suizo Émile Jaques-Dalcrozepara imaginar a su costa y a costa de la decadente cultura europea una feliz conjunción de Stravinsky y danzantes afrocubanos para «una danza realmente sometida a pulsiones elementales, primordiales» donde la Danse sacrale anterior al sacrificio derivase hacia la «histeria extática y gestual llevada al paroxismo» de una posesión $(C P, 260-262)$. La tarea de hacer realidad esa imaginación quedó también a cargo de Vera, como no podía ser menos, respaldada por su éxito en la formación de jóvenes bailarinas. Un paso más se dio cuando Mirta, cubana de ascendencia rusa, formó pareja de baile con Calixto, un mulato reclutado tras advertir en su improvisación magistral de la Danse sacrale la posibilidad de dar una nueva interpretación escénica a la música de Stravinski. Cabía sustituir el final agónico de la virgen electa por otro triunfal en el que el pas de deux de una pareja también electa simbolizase una ofrenda a la fertilidad y a la vida.

La dictadura de Fulgencio Batista, instaurada con un golpe de estado el 10 de marzo de 1952, significaría la irrupción violenta de la historia en las inquietudes estéticas de Vera, en los términos que cabía esperar: tras el asalto al cuartel Moncada, el 26 de julio de 1953, y la derrota de los subversivos, el espectáculo musical que La consagración de la primavera debería conformar junto a creaciones de músicos bien conocidos de Carpentier - los cubanos Manuel Saumell, Ernesto Lecuona, Amadeo Roldán y Alejandro García Caturla, el mexicano Silvestre Revueltas, el brasileño Heitor Villa-Lobos y el francoamericano Edgar Varèse- se vio frustrado por la represión que terminó con la vida de algunos bailarines, afectos al Movimiento 26 de Julio dirigido por Fidel Castro, mientras el Ejército Rebelde afincado en Sierra Maestra se empeñaba en conseguir la victoria final, confirmada el 1 de enero de 1959. El relato entusiasta de los hechos que significaron el triunfo de la Revolución y la consolidación del régimen castrista, con la integración ya decidida de sus personajes en ese prometedor mundo nuevo, hizo que Carpentier se olvidara de La consagración de la primavera en los últimos capítulos de su novela, aunque al final Vera se mostrara decidida a recuperar el antiguo proyecto, desaparecidos los obstáculos de antaño. Pero sus planteamientos habían quedado claros antes de que las circunstancias le impidieran llevarlos a la escena. La «euforia de rito triunfal» $\mathrm{y}$ el «gesto de exultación, de júbilo, de acción de gracias» con que Calixto había cerrado su improvisación de la Danse sacrale encerraban una significación profunda, que exigía a Vera liberarse de Roerich y de su dependencia de «los poetas adánicos rusos de los años $10 »$, y por tanto de la inmersión que aquellos habían hecho en «las fuentes primigenias de lo prehistórico, elemental y totémico» $(C P, 311)$. Esa significación se iría aclarando al recordar El sombrero de tres picos de Manuel de Falla, que con diseños de Pablo Picasso y coreografía de Léonide Massine los Ballets Rusos estrenaran el 26 de julio de 1919 en el Alhambra Theatre de Londres. Su evocación, algunos años después, permitiría a Vera recordarse - Carpentier la incluía como figurante entre los «vecinos» en una representación ubicada en París - convencida de que la inspiración hallada por Massine en los gitanos granadinos del Sacromonte significaba «una vuelta al baile popular, espontáneo, visceral, fuente primera de toda danza» $(C P, 501)$.

Increíblemente aquella joven bailarina, admiradora ferviente de la refinada Anna Pávlova, imaginaba ya entonces, para luego olvidarla durante mucho tiempo, una versión de La consagración de la primavera diferente de «la malísima, equivocadísima, de 
Nijinski y Maria Piltz» (la de 1913), y que habría de basarse en «danzas elementales, primitivas, hijas del instinto universal que lleva al ser humano a expresarse en un lenguaje gestual» $(C P, 501)$. Esa distracción no era la única sufrida por Carpentier, a quien la inmersión en las fuentes primigenias de lo prehistórico, elemental y totémico que habían efectuado los poetas adánicos rusos — los inspiradores de Roerich- no impedía declarar «fallida al nacer por buscarse soluciones intelectuales» $(C P, 501)$ aquella representación inicial. O quizá entendía ya que lo prehistórico, elemental y totémico no era sino otra creación intelectual modificable o sustituible, expuesta en todo caso a los ataques del antiintelectualismo en boga, lo que lo llevaba a optar por el lenguaje del cuerpo, al parecer capaz de expresar al compás de la música (y en especial de la percusión) las emociones más profundas. No en vano Vera declaraba finalmente preferir un espectáculo a cargo de bailarines educados «en la Gran Academia de Lo Que Se Lleva en la Sangre» $(C P, 413)$, concesión antiintelectualista muy acorde, por otra parte, con los planteamientos intelectuales que el propio Carpentier había deducido de la decadencia de Occidente proclamada en los ya lejanos años veinte. Pero los olvidos, las incoherencias e incluso los posibles anacronismos no impiden percibir el significado profundo de los cambios imaginados para la Danse sacrale de La consagración de la primavera, justificando el título de la novela. Vera, que más de una vez temió verse condenada a la tarea de arrastrar como Sísifo una existencia sin metas alcanzables, acertó a resumirlo: «Ahora no veía yo ese desenlace como un rito sacrificial sino como el ascendente rito vernal, propiciador de fecundidad, que debió de ser en sus albores» $(C P, 312)$. Fuera como fuese en su origen, el mito se descubría vulnerable a su tratamiento literario. Al acomodar la antigua y fatalista leyenda caucásica a las esperanzas en el futuro despertadas por la Revolución cubana, Carpentier enriquecía y compartía las opciones que en el tratamiento de los ingredientes míticos se abrían para la narrativa hispanoamericana en las últimas décadas del siglo XX. 
